\title{
VIVASIGHT SINGLE-LUMEN TUBE AS AN INTUBATION METHOD. A SYSTEMATIC REVIEW AND META-ANALYSIS OF RANDOMISED SIMULATION TRIALS
}

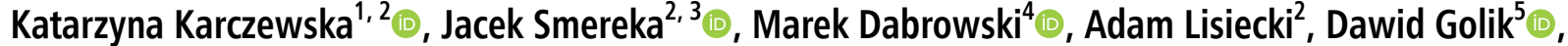 \\ Dominika Dunder ${ }^{2} \odot$, Szymon Bialka ${ }^{6} \odot$, Lukasz Szarpak ${ }^{2,5} \odot$, Kurt Ruetzler ${ }^{7} \odot$ \\ 'Department of Anesthesiology, Mazovian Specialist Hospital, Radom, Poland \\ ${ }^{2}$ Polish Society of Disaster Medicine, Warsaw, Poland \\ ${ }^{3}$ Department of Emergency Medical Service, Wroclaw Medical University, Wroclaw, Poland \\ ${ }^{4}$ Chair and Department of Medical Education, Poznan University of Medical Sciences, Poznan, Poland \\ ${ }^{5}$ Lazarski University, Warsaw, Poland \\ ${ }^{6}$ Department of Anaesthesiology and Intensive Care, Medical University of Silesia, Zabrze, Poland \\ ${ }^{7}$ Departments of Outcomes Research and General Anesthesiology, Anesthesiology Institute, Cleveland Clinic, Cleveland, Ohio, United States
}

\begin{abstract}
INTRODUCTION: Endotracheal intubation is one of the basic procedures performed in emergency medicine in patients with respiratory insufficiency, inability to maintain airway patency, or apnoea. Rapid performance of the procedure and implementation of ventilation are among the basic principles of rescue procedures. The primary aim of the present systematic review and meta-analysis was to compare the VivaSight single lumen (SL) tube-mounted camera with a standard endotracheal single-lumen tube and direct laryngoscope for endotracheal intubation based on randomised controlled trials of simulation or cadaver trials. The analysis was based on the hypothesis that the use of videolaryngoscopy based on VivaSight SL tube increases the effectiveness of endotracheal intubation, reducing the risk of ineffectiveness of the first intubation attempt and the risk of adverse events, such as dental compression.
\end{abstract}

MATERIAL AND METHODS: We searched the MEDLINE, EMBASE, Scopus, Cochrane, and Google Scholar databases for randomised, controlled trials and observational studies from 1985 until October 2019, without language restrictions. Grey literature, clinicaltrials.gov, and reference lists of articles were hand searched. We conducted a meta-analysis with random-effects models to evaluate time to intubation, first-pass success rates, overall success rates, dental compression, and glottic view.

RESULTS: The search located 12 eligible studies. The time of intubation using VivaSight was significantly shorter than that of direct laryngoscopy (MD $=-11.29[-13.10,-9.49], p<0.001)$. The efficacy of the first intubation attempt was higher for VivaSight than for double lumen (DL) $(96.0 \%$ vs. $61.7 \%$; RR $=1.62$ [1.40, $1.88], p<0.001)$. The meta-analysis showed that the total efficacy of VivaSight intubation compared to direct laryngoscopy was statistically significantly higher (100\% vs. $88.9 \%$, $R R=1.11[1.02,1.20] ; p=0.02)$. The glottis visibility assessed as Cormack-Lehane grade I or II was better in VivaSight intubation compared to direct laryngoscopy (100\% vs. $90.9 \%, R R=1.05[0.99,1.12] ; p=0.08)$.

CONCLUSIONS: Our meta-analysis suggests that the VivaSight SL provided better glottic visualisation and shorter intubation time, with improved success rates during different simulated intubation scenarios.

KEY WORDS: VivaSight; ETView; tube-mounted camera; endotracheal intubation; medical simulation; meta-analyses

Disaster Emerg Med J 2020; 5(1): 30-40 


\section{INTRODUCTION}

The protection of the airway in cardiopulmonary resuscitation (CPR) settings, similar to that of an injured patient, should be one of the basic procedures performed by medical personnel. If the airway patency cannot be secured, desaturation will occur quickly. Aerobic reserves of the body in normal conditions are sufficient for 3-5 minutes [1]. However, after this time, irreversible changes in vital organs occur, especially in the central nervous system, which is most susceptible to hypoxia. One of the basic methods of securing the airway patency under emergency settings used by emergency exit teams, similarly to the emergency department, is endotracheal intubation. This method allows, among other things, the use of positive end-expiratory pressure as well as asynchronous resuscitation, which, as shown by Ewy et al. [2], improves 24-hour post-resuscitation neurologically normal survival compared to 30:2 CPR. However, in pre-hospital conditions, special care should be taken and thus each patient should be treated as a patient with difficult airways, bearing in mind, among other things, that the patient may have a 'full stomach' as well as present difficulties in visualising the glottis. According to the study, despite the fact that endotracheal intubation is considered by many authors to be the golden standard of airway management, the effectiveness of intubation in emergency medicine is insufficient $[3,4]$.

Thanks to advances in medical technology, videolaryngoscopy can provide an alternative to direct laryngoscopy [5]. An example of a videolaryngoscope is the ETView VivaSight single lumen (SL) tube-mounted camera (ETView Ltd., Misgav, Israel). It is an intubation tube, which is equipped with an integrated camera that transmits the image from the end of the tube to the screen connected to it via a fibre-optic cable. If the camera lens is blurred by fluid from the mouth, it is possible to rinse the lens with a dedicated flushing system. Additionally, if the VivaSight SL deep endotracheal tube is inserted, it is possible to visualise the carina and introduce the bronchial blocker and one-lung ventilation without the need to confirm the position of the blocker with a fibroscope [6-8].

The primary aim of the present systematic review and meta-analysis was to compare the VivaSight SL tube-mounted camera with a standard endotracheal single-lumen tube and direct laryngoscope for endotracheal intubation based on randomised controlled trials of simulation or cadaver trials. The analysis was based on the hypothesis that the use of videolaryngoscopy based on VivaSight SL tube increases the effec- tiveness of endotracheal intubation, reducing the risk of ineffectiveness of the first intubation attempt and the risk of adverse events, such as dental compression.

\section{MATERIAL AND METHODS}

The systematic review followed the recommendations by the Preferred Reporting Items for Systematic Review and Meta-analysis (PRISMA) [9].

Accessing the MEDLINE, EMBASE, Scopus, Cochrane and Google Schollar databases, we performed a literature search for studies published between 1985 and October 2019 using the following search terms and key words: tube-mounted camera, ETView, VivaSight, endotracheal intubation. In addition, we manually checked the reference list of each article. Studies were eligible for inclusion if they were individually randomised or cluster randomised trials that compared the use of a VivaSight SL with a standard endotracheal tube for intubation in simulations on cadaver scenarios. There was no restriction of eligibility based on language of publication. After duplicate removal, title and abstract screening was performed independently by KK and SB using Endnote ${ }^{\circledR}$ (Clarivate Analytics, USA). Any discrepancies in the extracted data were resolved by reference to the original study, reaching consensus between LS and JS. Additional$l y$, the reference lists of included studies were also searched for potential studies. Studies were not included in the analyses if they reported insufficient information to allow assessment of their risk of bias. The review protocol was not pre-registered or published.

For each eligible study, we extracted information about the study's population and methodology, and the following outcomes; intubation time, success of first intubation attempt, overall intubation success rate, glottic view using Cormack-Lehane grade, and dental compression.

We used the Cochrane Risk of Bias tool to assess the studies' risk of bias. This assesses seven domains: generation of random allocation sequence, allocation concealment, blinding of participants and study personnel, blinding of outcome assessment, incomplete outcome data, selective reporting, and other sources of bias. For each study, we assessed the methods used to address each potential source of bias and summarised them in tabular form.

\section{Statistical analysis}

For statistical analyses we used Review Manager (RevMan) software version 5.3. Because there may 


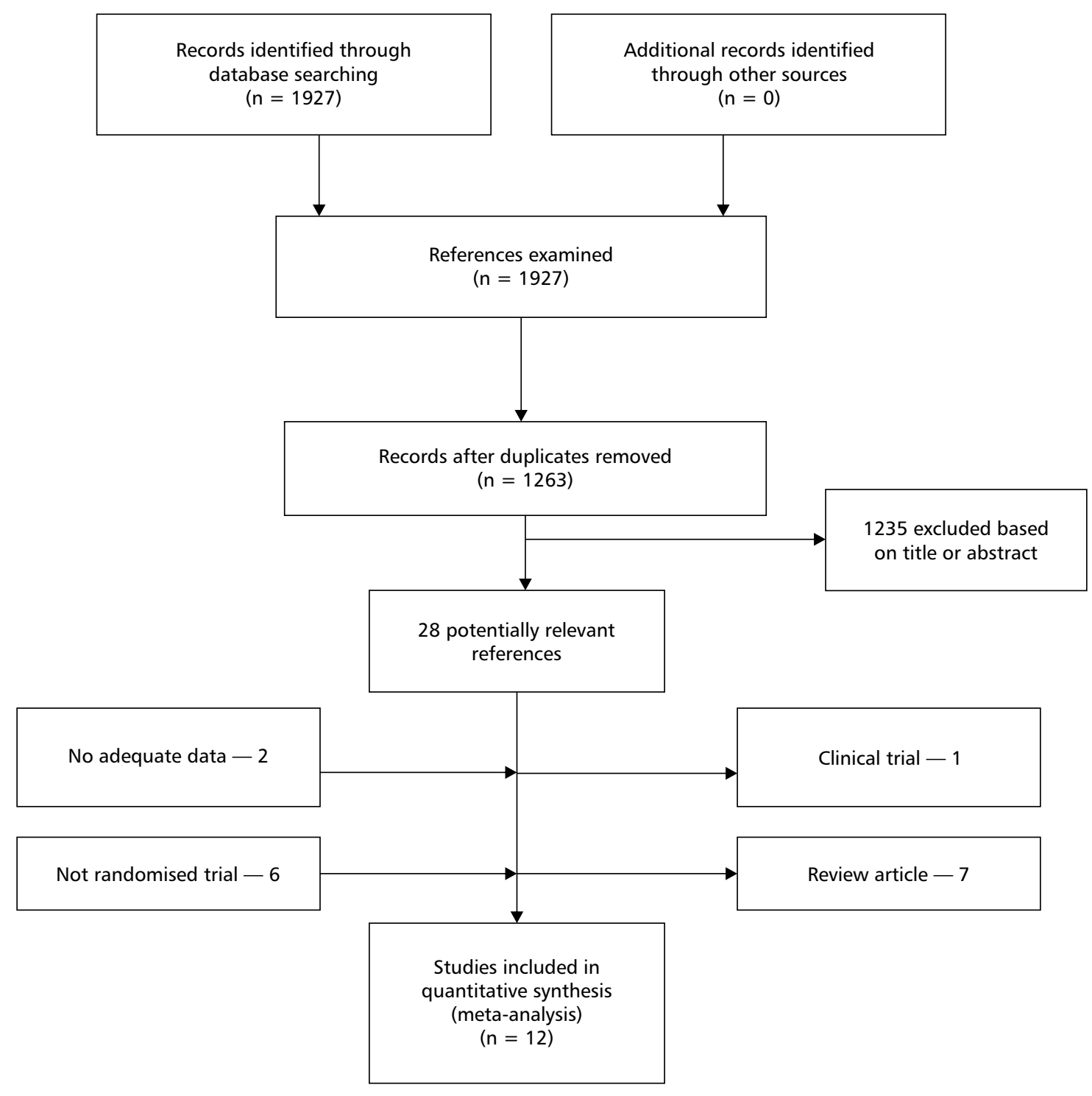

FIGURE 1. Flow diagram of study selection

be differences in the treatment effect between trials, especially those using different devices, we used a random-effects model. We also calculated 95\% prediction intervals, to estimate the range of plausible treatment effects. For continuous outcomes (e.g. intubation time) we used the mean difference (MD), and for dichotomous outcomes (e.g. first attempt success rate) we calculated risk ratios (RR). All statistical variables were calculated with 95\% confidence interval (Cl). When the continuous outcome was reported in some studies as median, range, and interquartile range, we estimated means and standard deviations using the formula described by Hozo et al. [10]. We quantified heterogeneity in each analysis by the tau-squared and I-squared statistics. Studies were subgrouped by the type of intubation scenarios. We summarised categorical data using RR according to the Mantel-Haenszel method and a random-effects model. Heterogeneity was detected with a chi-square test with $n-1$ degrees of freedom, which was expressed as $I^{2}$. When the $I^{2}$ statistic was $>50 \%$, statistical heterogeneity was considered to be relevant. Sensitivity analyses were performed to further explore heterogeneity by excluding high weights in pooled studies and excluding studies that used discharge destination as a surrogate for the neurological outcome.

\section{RESULTS}

The search located 13 eligible studies [11-21] (Fig. 1). One study was carried out on a cadaver [21], and the remaining studies were strictly simulation studies using medical simulators imitating adult pa- 


\begin{tabular}{|c|c|c|c|c|}
\hline Citation & $\begin{array}{l}\text { Intubation } \\
\text { techniques used } \\
\text { (number of } \\
\text { participants) }\end{array}$ & Study design & Scenarios & Participants \\
\hline $\begin{array}{l}\text { Dabrowski et al. } \\
2017[11]\end{array}$ & $\begin{array}{l}\text { VivaSight SL: } 57 \\
\text { DL: } 57\end{array}$ & $\begin{array}{l}\text { Randomised } \\
\text { crossover }\end{array}$ & $\begin{array}{l}\text { 1. Normal airway without chest compression } \\
\text { 2. Normal airway with uninterrupted chest compression }\end{array}$ & $\begin{array}{l}\text { Novice } \\
\text { physicians }\end{array}$ \\
\hline $\begin{array}{l}\text { Gawlowski et } \\
\text { al. } 2017 \text { [12] }\end{array}$ & $\begin{array}{l}\text { VivaSight SL: } 67 \\
\text { DL: } 67\end{array}$ & $\begin{array}{l}\text { Randomised } \\
\text { crossover }\end{array}$ & $\begin{array}{ll}\text { 1. } & \text { Normal airway } \\
\text { 2. Cervical spine with manual stabilisation } \\
\text { 3. Cervical spine with cervical collar stabilisation }\end{array}$ & $\begin{array}{l}\text { Novice } \\
\text { physicians }\end{array}$ \\
\hline $\begin{array}{l}\text { Karczewska et } \\
\text { al. } 2017 \text { [13] }\end{array}$ & $\begin{array}{l}\text { VivaSight SL: } 50 \\
\text { DL: } 50\end{array}$ & $\begin{array}{l}\text { Randomised } \\
\text { crossover }\end{array}$ & $\begin{array}{l}\text { 1. Normal standard airway } \\
\text { 2. Cervical spine with cervical collar stabilisation } \\
\text { 3. Cervical immobilisation using a vacuum mattress }\end{array}$ & Physicians \\
\hline $\begin{array}{l}\text { Kurowski et al. } \\
2015[14]\end{array}$ & $\begin{array}{l}\text { VivaSight SL: } 107 \\
\text { DL: } 107\end{array}$ & $\begin{array}{l}\text { Randomized } \\
\text { crossover }\end{array}$ & $\begin{array}{l}\text { 1. Normal airway without chest compression } \\
\text { 2. Normal airway with uninterrupted chest compression }\end{array}$ & $\begin{array}{l}\text { Novice } \\
\text { physicians }\end{array}$ \\
\hline $\begin{array}{l}\text { Madziala et al. } \\
2016[15]\end{array}$ & $\begin{array}{l}\text { VivaSight SL: } 62 \\
\text { DL: } 62\end{array}$ & $\begin{array}{l}\text { Randomised } \\
\text { crossover }\end{array}$ & Face-to-face intubation & Paramedics \\
\hline $\begin{array}{l}\text { Madziala } 2018 \\
{[16]}\end{array}$ & $\begin{array}{l}\text { VivaSight SL: } 52 \\
\text { DL: } 52\end{array}$ & $\begin{array}{l}\text { Randomised } \\
\text { crossover }\end{array}$ & Cervical spine with cervical collar stabilisation & Nurses \\
\hline $\begin{array}{l}\text { Madziala et al. } \\
2018 \text { [2016??] } \\
{[15]}\end{array}$ & $\begin{array}{l}\text { VivaSight SL: } 45 \\
\text { DL: } 45\end{array}$ & $\begin{array}{l}\text { Randomised } \\
\text { crossover }\end{array}$ & Normal airway with uninterrupted chest compression & $\begin{array}{l}\text { Last year } \\
\text { medical } \\
\text { students }\end{array}$ \\
\hline $\begin{array}{l}\text { Stawicka et al. } \\
2016[17]\end{array}$ & $\begin{array}{l}\text { VivaSight SL: } 47 \\
\text { DL: } 47\end{array}$ & $\begin{array}{l}\text { Randomised } \\
\text { crossover }\end{array}$ & $\begin{array}{l}\text { 1. Normal airway without chest compression } \\
\text { 2. Normal airway with uninterrupted chest compression }\end{array}$ & Nurses \\
\hline $\begin{array}{l}\text { Szarpak et al. } \\
2016 \text { (A) [18] }\end{array}$ & $\begin{array}{l}\text { VivaSight SL: } 56 \\
\text { DL: } 56\end{array}$ & $\begin{array}{l}\text { Randomised } \\
\text { crossover }\end{array}$ & $\begin{array}{l}\text { 1. Cervical spine with cervical collar stabilisation } \\
\text { 2. Cervical spine with cervical collar stabilisation } \\
\text { (+tongue oedema) }\end{array}$ & Paramedics \\
\hline $\begin{array}{l}\text { Szarpak et al. } \\
2016 \text { (B) [19] }\end{array}$ & $\begin{array}{l}\text { VivaSight SL: } 29 \\
\text { DL: } 29\end{array}$ & $\begin{array}{l}\text { Randomised } \\
\text { crossover }\end{array}$ & Cervical spine with manual stabilisation under resuscitation & Physicians \\
\hline $\begin{array}{l}\text { Truszewski et al. } \\
2016 \text { (A) [20] }\end{array}$ & $\begin{array}{l}\text { VivaSight SL: } 45 \\
\text { DL: } 45\end{array}$ & $\begin{array}{l}\text { Randomised } \\
\text { crossover }\end{array}$ & $\begin{array}{l}\text { Patient trapped in car (trauma patient intubation face to } \\
\text { face) }\end{array}$ & Paramedics \\
\hline $\begin{array}{l}\text { Truszewski et al. } \\
2016 \text { (B) [21] }\end{array}$ & $\begin{array}{l}\text { VivaSight SL: } 52 \\
\text { DL: } 52\end{array}$ & $\begin{array}{l}\text { Randomised } \\
\text { crossover }\end{array}$ & $\begin{array}{l}\text { 1. Normal airway without chest compression } \\
\text { 2. Normal airway with uninterrupted chest compression } \\
\text { 3. Cervical spine with manual stabilisation }\end{array}$ & Paramedics \\
\hline
\end{tabular}

tients. Study characteristics are summarised in Table 1. Figures 2 and 3 summarise the risk of bias of the included trials.

\section{Time to intubation}

The analysis showed that the time of VivaSight intubation was significantly shorter than that of direct laryngoscopy (MD $=-11.29$ [-13.10, -9.49], $p<0.001$; Fig. 4). The analysis in subgroups showed that the above trend was observed in each subgroup, including: normal airway $(\mathrm{MD}=-7.52[-10.14,-4.90], \mathrm{p}<0.001)$; cervical spine manual immobilisation (MD $=-8.82[-12.26$, $-5.38], p<0.001)$, cervical spine immobilisation with cervical collar (MD $=-10.84[-13.58,-8.11]$, $p<0.001)$, intubation during continuous chest compression ( $\mathrm{MD}=-17.47[-19.88,-15.05]$, $p<0.001)$, and all others.

\section{First intubation attempt success rate}

The effectiveness of the first intubation attempt was higher with VivaSight than with double lumen (DL) (96.0\% vs. $61.7 \% ; R R=1.62[1.40,1.88], p<0.001$, $1^{2}=93 \%$; Fig. 5). VivaSight intubation was superior to direct intubation in each scenario: normal airway $(98.7 \%$ vs. $71.4 \% ; R R=1.41[1.18,1.69]$, $p<0.001)$, cervical spine manual immobilisation (96.2\% vs. $70.3 \% ; R R=1.51[0.93,2.44], p=0.10)$, cervical spine immobilisation with cervical collar (95.6\% vs. $43.1 \% ; R R=2.29[1.37,3.85], p=0.002$ ), and continuous chest compression $(92.7 \%$ vs. $47.0 \%$; $R R=12.00[1.35,2.97], p<0.001)$. One study [13] assessed intubation in cervical spine immobilisation with a vacuum mattress scenario and also showed the advantage of VivaSight over DL ( $90 \%$ vs. $60 \%$; $R R=1.50[1.17,1.92] ; p=0.001)$. In contrast, the Truszewski et al. [20] study showed the advantage of 


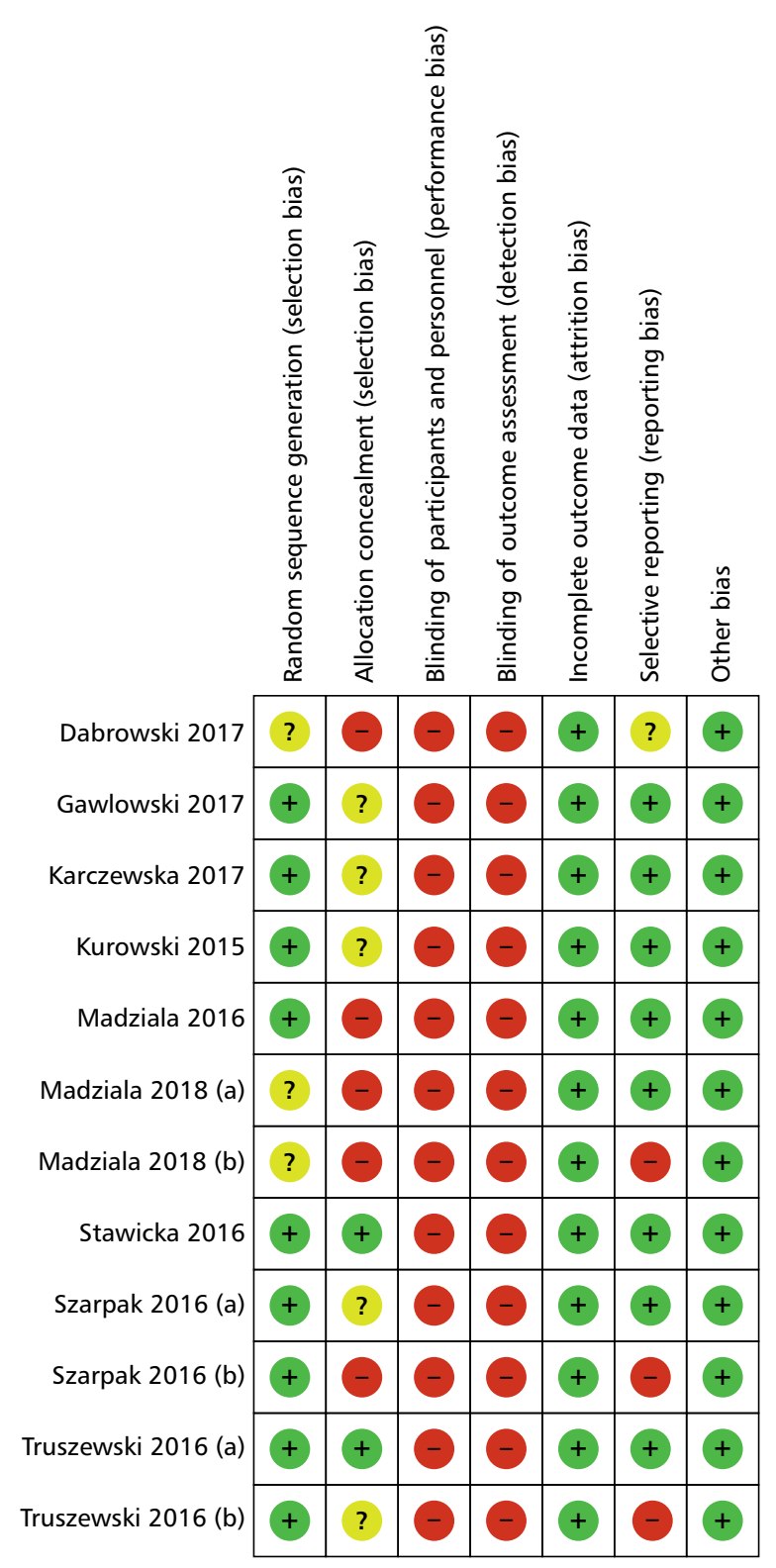

FIGURE 2. Evaluation of bias in all included studies across the various domains
VivaSight over DL in the case of face-to-face intubation of a patient stuck in a vehicle (100\% vs. $86.7 \%$; $R R=1.15[1.02,1.30] ; p=0.02)$.

\section{Overall intubation success rate}

The meta-analysis showed that the efficacy of VivaSight intubation compared to direct laryngoscopy was significantly higher $(100 \%$ vs. $88.9 \%$, $R R=1.11[1.02,1.20] ; p=0.02 ;$ Fig. 6). The analysis in subgroups also showed higher total efficacy of VivaSight intubation compared to direct laryngoscopy in a normal airway scenario (100\% vs. 94.8\%, $R R=1.04[0.96,1.13] ; p=0.33)$, cervical spine immobilisation with cervical collar (100\% vs. 93.2\%, $R R=1.09[0.79,1.50] ; p=0.61)$, and continuous chest compression scenario (100\% vs. $63.6 \%$, $R R=1.61[1.27,2.03] ; p<0.001)$. Viva Sight intubation compared to direct laryngoscopy showed total efficacy of $100 \%$ for both intubation methods for cervical spine manual immobilisation, cervical immobilisation with vacuum mattress, as well as in face-to-face intubation scenarios.

\section{Glottic view}

The glottis was better visualised at the level of Cormack-Lehane grade I or II for intubation using VivaSight than with direct laryngoscopy (100\% vs. 90.9\%, $\mathrm{RR}=1.05[0.99,1.12] ; \mathrm{p}=0.08 ;$ Fig. 7). The same level of vocal visibility was observed for VivaSight and direct laryngoscopy for normal airway scenarios as well as cervical immobilisation with vacuum mattress scenarios. Better visibility of the glottis in VivaSight compared to direct laryngoscope was observed in cervical spine manual immobilisation scenarios (100\% vs. $94.9 \%, R R=1.05[1.00,1.10] ; p=0.04)$, cervi-

Random sequence generation (selection bias)

Allocation concealment (selection bias)

Blinding of participants and personnel (performance bias)

Blinding of outcome assessment (detection bias)

Incomplete outcome data (attrition bias)

Selective reporting (reporting bias)

Other bias

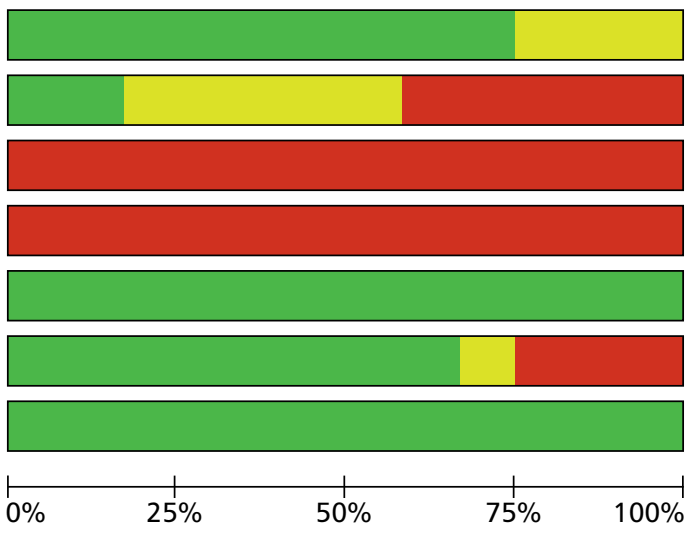

Low risk of bias

Unclear risk of bias

High risk of bias

FIGURE 3. Summary of risk of bias among included studies 


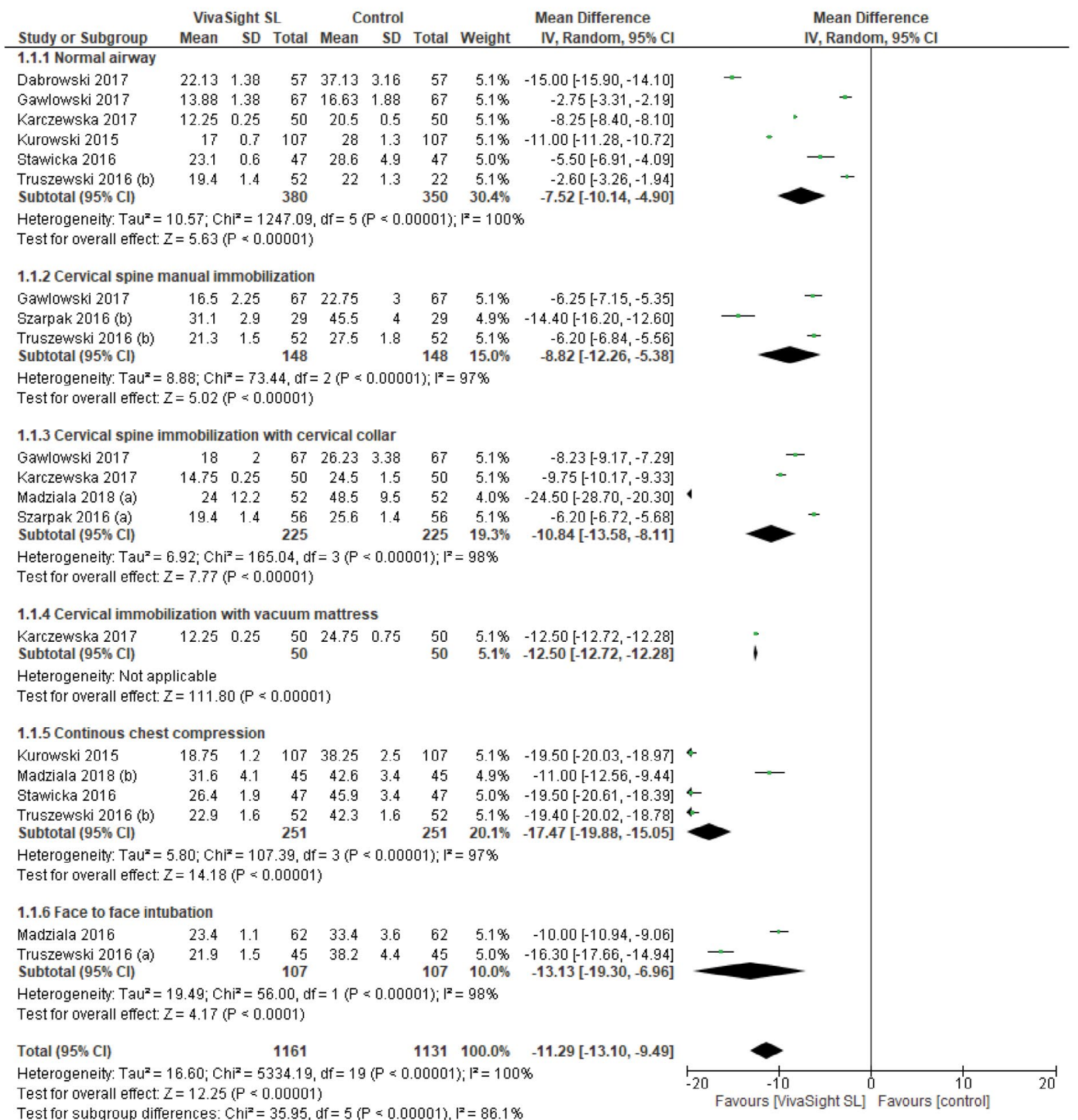

FIGURE 4. Time to intubation

cal spine immobilisation with cervical collar scenarios ( $100 \%$ vs. $48.7 \%, R R=2.11[0.61,7.30] ; p=0.24$ ), as well as in continuous chest compression scenarios $(100 \%$ vs. $96.6 \%, R R=1.02[0.97,1.07] ; p=0.42)$.

\section{Dental compression}

Less dental pressure was observed for VivaSight than for direct laryngoscopy (Fig. 8; $p<0.001$ ). This relationship was also present in each of the analysed subgroups: normal airway, cervical spine immobilisation with cervical collar, as well as cervical immobilisation with vacuum mattress.

\section{DISCUSSION}

The study included a meta-analysis of endotracheal intubation using a standard endotracheal tube relative to a tube with a built-in ETView video track.

Intubation under emergency medicine conditions is an extremely important procedure; however, there is a high risk of failure. According to the Park et al. study, the effectiveness of the first intubation attempt in the emergency department is $84.1 \%$ for all patients and $81.8 \%$ for trauma patients [22]. These results are also confirmed by the study by Kerslake et al., where the effectiveness of the first intubation 


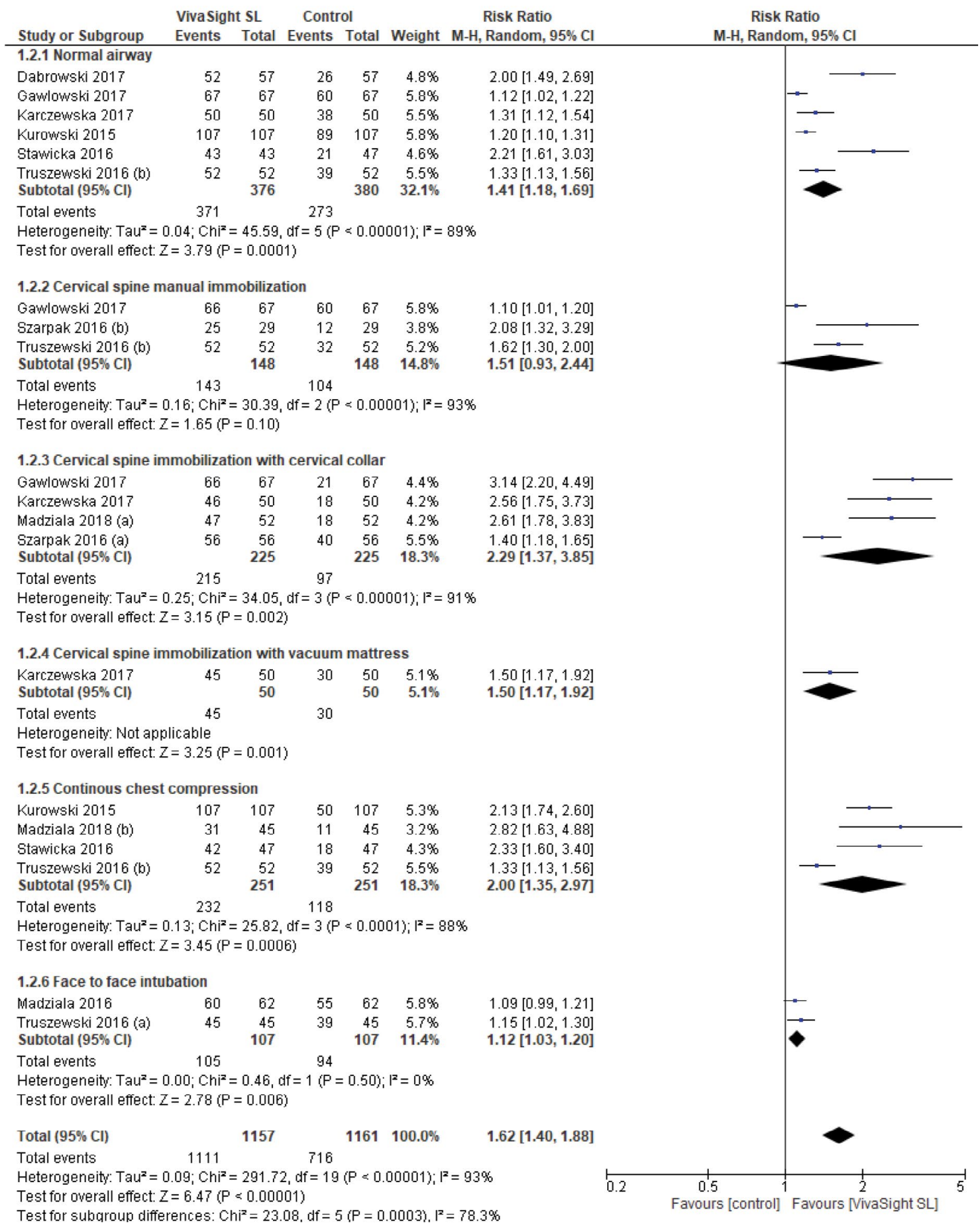

FIGURE 5. First intubation success rate

attempt by emergency physicians and anaesthetists was $85 \%$ [23]. In emergency medicine, due to progressive hypoxia and the necessity to perform other medical procedures, it is essential to perform endotracheal intubation in the shortest possible time and in relatively few attempts. Repeated attempts of intubation may result in oedema of soft tissues and bleeding, which may lead to a vicious circle in which each subsequent intubation attempt intensifies the mentioned complications leading to the situation 


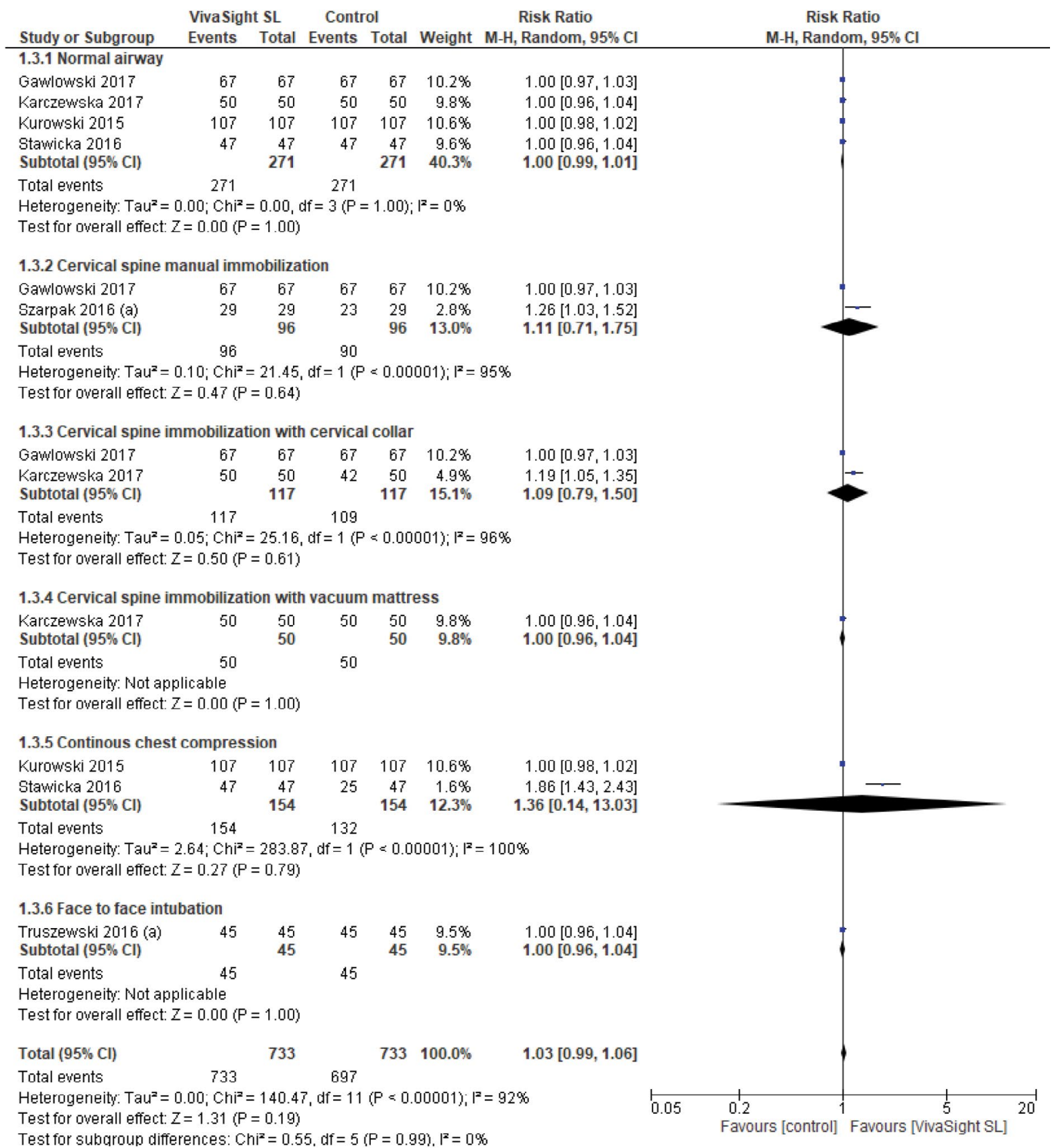

FIGURE 6. Overall success rate

described by the Difficult Airway Society as 'Can't intubate, can't ventilate' $[24,25]$. Then the only possible salvation is cricothyroidotomy.

The meta-analysis demonstrated that the use of VivaSight SL was associated with markedly higher efficacy of the first intubation attempt compared to standard direct laryngoscopy for both the overall analysis and subgroup analysis. On the other hand, the overall efficacy of intubation was superior for VivaSight SL than for direct laryngoscope. The above tendency concerned both the total meta-analysis outcome and subgroup analysis, particularly intubation under normal airway, cervical spine immobilisation with cervical collar, or continuous chest compression scenarios. In the case of the overall success rate of intubation, Karczewska et al. demonstrated that intubators were able to intubate patients with a 100\% success rate for both VivaSight and direct laryngoscope under cervical spine immobilisation with a vacuum mattress [13]. 100\% effectiveness of intubation with the discussed methods was also observed by Gawłowski et al. in the cervical spine man- 


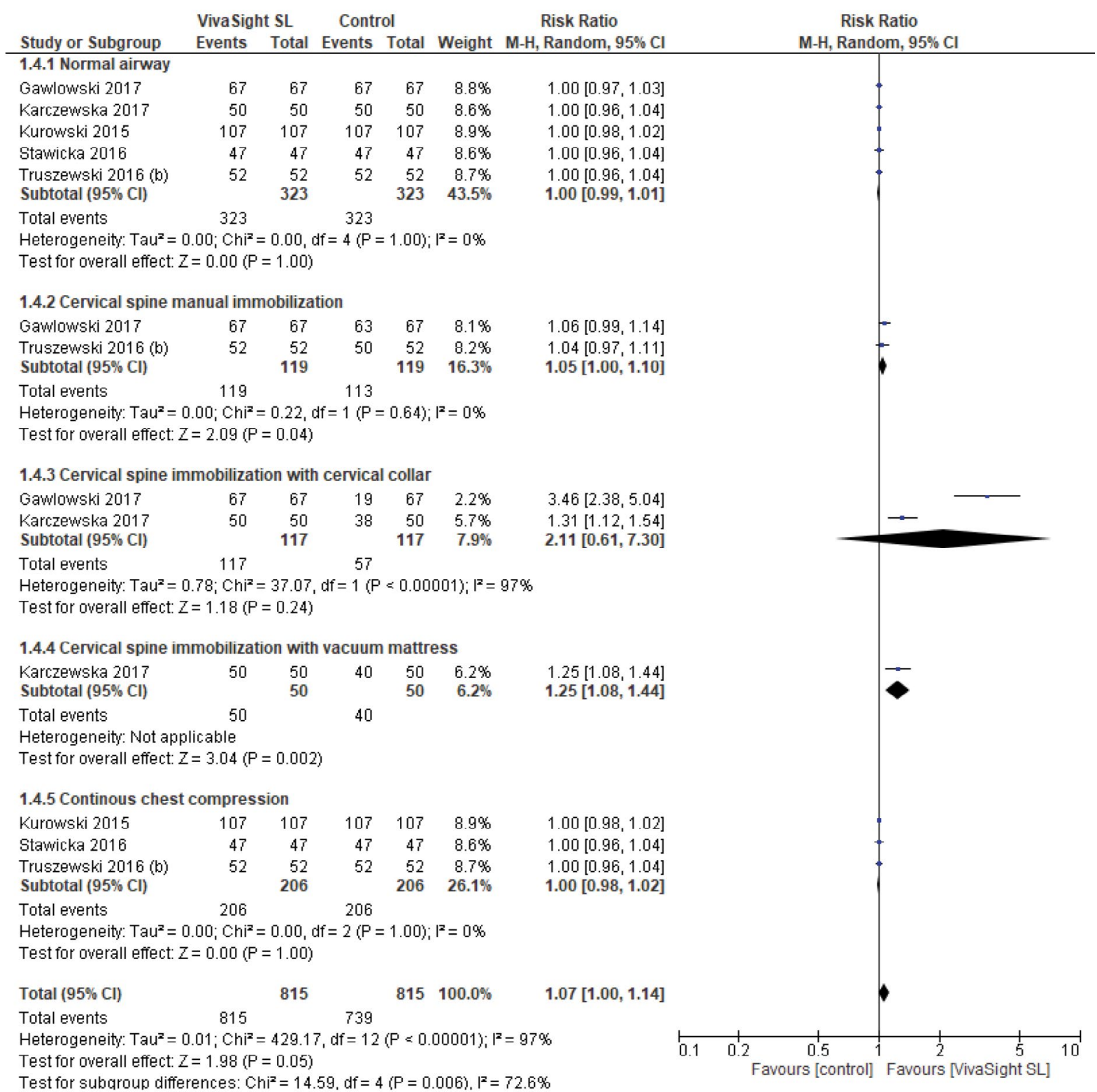

FIGURE 7. Glottis view according to Cormack-Lehane grade I or II

ual immobilisation scenario [12], as well as Truszewski et al. intubating patients face to face [20]. The above results are all the more important because the personnel participating in them (physicians, nurses, or paramedics) had no previous experience in videolaryngoscopy. Therefore, this shows a short curve of teaching intubation using VivaSight SL.

Rapid endotracheal intubation reduces the risk of hypoxia and allows the introduction of mechanical ventilation with a ventilator, allowing the medical personnel to focus on other procedures [26, 27]. This is particularly important in the context of emergency teams, where a limited number of personnel in the team forces therapeutic compro- mises. According to the meta-analysis, intubation with VivaSight compared to direct laryngoscopy was associated with significantly shorter procedure time.

The performed meta-analysis has certain limitations. The main limitation of the articles included in the study is the fact that all of them were conducted under medical simulation conditions. However, this fact was deliberate because all the studies are randomised and only one study, by Barak et al. [28], was a randomised clinical trial analysing the efficacy of VivaSight SL carried out under real patient intubation conditions. Additionally, simulation studies allow for full standardisation of the difficulties of the procedures performed, and at the same time for 


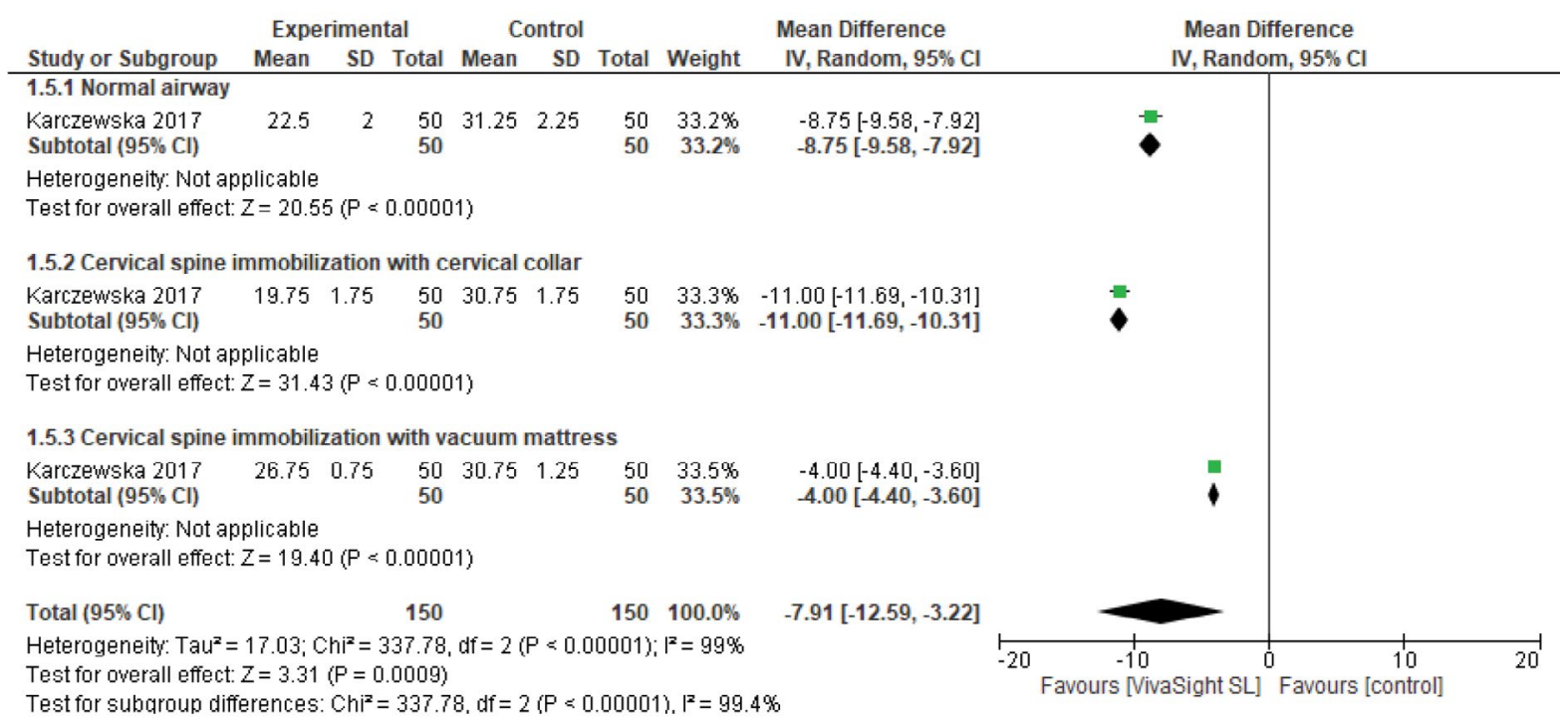

FIGURE 8. Dental injuries

unrestricted repeatability of the procedures without any health detriment to the potential patient. Due to the value of medical simulation in the process of medical education, studies conducted under simulated conditions also have a high impact on clinical practice. However, it is known that they cannot be directly transposed into practice with a real patient because the efficacy can be reduced and the time of the procedure can be extended; however, the differences between the devices are usually maintained.

\section{CONCLUSIONS}

Our meta-analysis suggests that the VivaSight SL provided better glottic visualisation and shorter intubation time, with improved success rates during different simulated intubation scenarios.

\section{Acknowledgement}

Study supported by Polish Society of Disaster Medicine.

\section{REFERENCES}

1. Bodily JB, Webb HR, Weiss SJ, et al. Incidence and Duration of Continuously Measured Oxygen Desaturation During Emergency Department Intubation. Ann Emerg Med. 2016; 67(3): 389-395, doi: 10.1016/j. annemergmed.2015.06.006, indexed in Pubmed: 26164643.

2. Ewy GA, Zuercher M, Hilwig RW, et al. Improved neurological outcome with continuous chest compressions compared with 30:2 compressions-to-ventilations cardiopulmonary resuscitation in a realistic swine model of out-of-hospital cardiac arrest. Circulation. 2007; 116(22): 2525-2530, doi: 10.1161/CIRCULATIONAHA.107.711820, indexed in Pubmed: 17998457.
3. Bai W, Golmirzaie K, Burke C, et al. Evaluation of emergency pediatric tracheal intubation by pediatric anesthesiologists on inpatient units and the emergency department. Paediatr Anaesth. 2016; 26(4): 384-391, doi: 10.1111/pan.12839, indexed in Pubmed: 26738465.

4. Sulser S, Ubmann D, Schlaepfer M, et al. C-MAC videolaryngoscope compared with direct laryngoscopy for rapid sequence intubation in an emergency department: A randomised clinical trial. Eur J Anaesthesiol. 2016; 33(12): 943-948, doi: 10.1097/EJA.00000000000000525, indexed in Pubmed: 27533711.

5. Markic S. Endotracheal tube ETView as a tool for airway management. Disaster and Emergency Medicine Journal. 2018; 3(4): 152-153, doi: 10.5603/demj.2018.0032.

6. Moritz A, Schreiner W, Schmidt J. One-lung ventilation after rapid-sequence intubation: a novel approach using an ETView tracheoscopic ventilation tube for placement of an EZ-Blocker without bronchoscopy. J Clin Anesth. 2016; 29: 48-49, doi: 10.1016/j.jclinane.2015.10.013, indexed in Pubmed: 26897448.

7. Karczewska K, Smereka J, Szarpak L, et al. Successful one-lung ventilation using the VivaSight-EB bronchial blocker tube for an emergency lung injury. A simulation pilot data. Disaster and Emergency Medicine Journal. 2019; 4(4): 131-136, doi: 10.5603/demj.a2019.0025.

8. Umutoglu T, Bakan M, Topuz U, et al. Comparison of EtView ${ }^{\text {TM }}$ tracheoscopic ventilation tube and video-assisted fiberoptic bronchoscopy during percutaneous dilatational tracheostomy. J Clin Monit Comput. 2017; 31(3): 507-512, doi: 10.1007/s10877-016-9885-x, indexed in Pubmed: 27130402.

9. Moher D, Liberati A, Tetzlaff J, et al. PRISMA Group, Preferred reporting items for systematic reviews and meta-analyses: the PRISMA Statement. BMJ 2009; 339: b2535, doi: 10.1136/bmj.b2535.

10. Hozo SP, Djulbegovic B, Hozo I. Estimating the mean and variance from the median, range, and the size of a sample. BMC Med Res Methodol. 2005; 5: 13, doi: 10.1186/1471-2288-5-13, indexed in Pubmed: 15840177. 
11. Dabrowski M, Dabrowska A, Wieczorek W, et al. Is ETView SL better than a standard direct laryngoscopy for novice physicians in the simulated resuscitation? Resuscitation. 2017; 118: e43-e44, doi: 10.1016/j.resuscitation.2017.08.109.

12. Gawlowski P, Smereka J, Madziala M, et al. Comparison of the ETView Single Lumen and Macintosh laryngoscopes for endotracheal intubation in an airway manikin with immobilized cervical spine by novice paramedics: A randomized crossover manikin trial. Medicine (Baltimore). 2017; 96(16): e5873, doi: 10.1097/MD.0000000000005873, indexed in Pubmed: 28422820.

13. Karczewska K, Szarpak L, Smereka J, et al. ET-View compared to direct laryngoscopy in patients with immobilized cervical spine by unexperienced physicians: A randomized crossover manikin trial. Anaesthesiol Intensive Ther. 2017; 49(4): 274-282, doi: 10.5603/AlT.a2017.0047, indexed in Pubmed: 28953308.

14. Kurowski A, Szarpak L, Truszewski Z, et al. Can the ETView VivaSight SL Rival Conventional Intubation Using the Macintosh Laryngoscope During Adult Resuscitation by Novice Physicians?: A Randomized Crossover Manikin Study. Medicine (Baltimore). 2015; 94(21): e850, doi: 10.1097/MD.0000000000000850, indexed in Pubmed: 26020389.

15. Madziala A, Majer J, Madziała M. Comparison of ETView SL, Airtraq, and Macintosh laryngoscopes for face-to-face tracheal intubation: a randomized crossover manikin trial. Am J Emerg Med. 2016; 34(9): 1893-1894, doi: 10.1016/j.ajem.2016.06.074, indexed in Pubmed: 27372222.

16. Madziała M. The ETView tracheoscopic ventilation tube for trauma patient intubation. Disaster and Emergency Medicine Journal. 2018; 3(2): 69-70, doi: 10.5603/demj.2018.0016.

17. Stawicka I, Czyzewski L, Smereka J, et al. Comparison of four laryngoscopes for orotracheal intubation by nurses during resuscitation with and without chest compressions: a randomized crossover manikin trial. Disaster and Emergency Medicine Journal. 2016; 1(1): 14-23, doi: 10.5603/demj.2016.0003.

18. Szarpak $Ł$, Truszewski Z, Kurowski A, et al. Tracheal intubation with a VivaSight-SL endotracheal tube by paramedics in a cervical-immobilized manikin. Am J Emerg Med. 2016; 34(2): 309-310, doi: 10.1016/j. ajem.2015.10.013, indexed in Pubmed: 26597329.

19. Szarpak L, Smereka J, Ruetzler K. Abstracts of the Scientific Symposium on Emergency Medicine 2016, 28-29 October 2016. Hong Kong Journal of Emergency Medicine. 2017; 23(5): 307-317, doi: $10.1177 / 102490791602300511$.
20. Truszewski Z, Szarpak Ł, Smereka J, et al. Comparison of the VivaSight single lumen endotracheal tube and the Macintosh laryngoscope for emergency intubation by experienced paramedics in a standardized airway manikin with restricted access: a randomized, crossover trial. Am J Emerg Med. 2016; 34(5): 929-930, doi: 10.1016/j. ajem.2016.02.054, indexed in Pubmed: 26979260.

21. Truszewski Z, Krajewski $P$, Fudalej $M$, et al. A comparison of a traditional endotracheal tube versus ETView SL in endotracheal intubation during different emergency conditions: A randomized, crossover cadaver trial. Medicine (Baltimore). 2016; 95(44): e5170, doi: 10.1097/ MD.0000000000005170, indexed in Pubmed: 27858851.

22. Park L, Zeng I, Brainard A. Systematic review and meta-analysis of first-pass success rates in emergency department intubation: Creating a benchmark for emergency airway care. Emerg Med Australas. 2017; 29(1): 40-47, doi: 10.1111/1742-6723.12704, indexed in Pubmed: 27785883.

23. Kerslake D, Oglesby AJ, Di Rollo N, et al. EDIR investigators. Tracheal intubation in an urban emergency department in Scotland: a prospective, observational study of 3738 intubations. Resuscitation. 2015; 89: 20-24, doi: 10.1016/j.resuscitation.2015.01.005, indexed in Pubmed: 25613360.

24. Higgs A, McGrath BA, Goddard C, et al. Difficult Airway Society. DAS guidelines on the airway management of critically ill patients. Anaesthesia. 2018; 73(8): 1035-1036, doi: 10.1111/anae.14352, indexed in Pubmed: 30117585.

25. Duggan LV, Ballantyne Scott B, Law JA, et al. Transtracheal jet ventilation in the 'can't intubate can't oxygenate' emergency: a systematic review. Br J Anaesth. 2016; 117 (Suppl 1): i28-i38, doi: 10.1093/bja/ aew192, indexed in Pubmed: 27566790.

26. Gerardi MJ, Sacchetti AD, Cantor RM, et al. Rapid-sequence intubation of the pediatric patient. Pediatric Emergency Medicine Committee of the American College of Emergency Physicians. Ann Emerg Med. 1996; 28(1): 55-74, doi: 10.1016/s0196-0644(96)70140-3, indexed in Pubmed: 8669740.

27. Miller KA, Nagler J. Advances in Emergent Airway Management in Pediatrics. Emerg Med Clin North Am. 2019; 37(3): 473-491, doi: 10.1016/j.emc.2019.03.006, indexed in Pubmed: 31262416.

28. Barak M, Putilov V, Meretyk S, et al. ETView tracheoscopic ventilation tube for surveillance after tube position in patients undergoing percutaneous nephrolithotomy. Br J Anaesth. 2010; 104(4): 501-504, doi: 10.1093/bja/aeq024, indexed in Pubmed: 20185518. 